\title{
Association of High Blood Pressure with Body Mass Index, Smoking and Physical Activity in Healthy Young Adults
}

George Papathanasiou ${ }^{1, *}$, Efthimia Zerva ${ }^{2}$, Ioannis Zacharis ${ }^{2}$, Maria Papandreou ${ }^{2}$, Effie Papageorgiou ${ }^{3}$, Christina Tzima ${ }^{4}$, Dimitris Georgakopoulos ${ }^{5}$ and Angelos Evangelou ${ }^{6}$

\author{
${ }^{I}$ Department of Physiotherapy, Technological Educational Institution (TEI) of Athens, Greece \\ ${ }^{2}$ Department of Physiotherapy, TEI of Athens, Greece \\ ${ }^{3}$ Department of Medical Laboratories, TEI of Athens, Greece \\ ${ }^{4}$ Laboratory of Physiology, Medical School, University of Ioannina, Greece \\ ${ }^{5}$ Department of Cardiology, "P \& Aglaia Kyriakou” Childrens' Hospital of Athens, Greece \\ ${ }^{6}$ Laboratory of Physiology, Medical School, University of Ioannina, Greece
}

\begin{abstract}
Introduction: The purpose of this study was to examine the associations between resting blood pressure (BP), smoking, physical activity (PA) and body mass index (BMI) in Greek young adults.

Materials and Methodology: A standardised questionnaire and the Greek version of IPAQ-short were given to 1500 randomly selected health science students, in order to record smoking behaviour, PA status, BMI and resting BP. All healthy young adults aged 19-30 years old were eligible. The final size of the study cohort was 1249 students (522 men).

Results: Males' BP was 129.2/77.0 $\mathrm{mmHg}$, significantly higher than the females' values of $119.9 / 73.4 \mathrm{mmHg}$. Approximately $17 \%$ of the total population were classified as overweight and $3 \%$ as obese. In the overall population, smoking prevalence was $35.2 \%$, with $15.3 \%$ being heavy smokers $(\geq 21$ cigs/d). Smoking prevalence did not differ significantly between sexes. The prevalence of health-enhancing PA (high $\mathrm{PA}_{\text {class }}$ ) was only $14.0 \%$, while $42.8 \%$ of the study population were classified as insufficiently active (low $\mathrm{PA}_{\text {class }}$ ). Of the three lifestyle risk factors examined, only BMI was significantly and directly associated with systolic and diastolic BP levels. The prevalence of hypertension $(\geq 140 / 90 \mathrm{mmHg})$ was significantly higher in men compared to women, and in obese and overweight participants compared to normal-weight subjects. Smoking and categorical PA ( $\left.\mathrm{PA}_{\text {class }}\right)$ were not correlated with BP. Continuous vigorous $\mathrm{PA}_{\text {score }}$ was significantly and directly associated with systolic $\mathrm{BP}$, but only in males.

Conclusion: BMI was significantly and directly associated with resting BP in both sexes. Smoking prevalence and PA status were not associated with BP in this sample of Greek young adults.
\end{abstract}

Keywords: Blood pressure, body mass index, obesity, physical activity, risk factors, smoking.

\section{INTRODUCTION}

High blood pressure (BP) is a major global health risk, affecting 1 billion people worldwide [1]. High BP is estimated to cause 7.5 million deaths worldwide, about $12.8 \%$ of the total of all deaths, and it accounts for 57 million disability-adjusted life years (DALYS), or 3.7\% of the total DALYS [2]. Globally, the overall prevalence of high blood pressure (systolic BP $\geq 140 \mathrm{mmHg}$ and/or diastolic BP $\geq 90 \mathrm{mmHg}$ ) in adults exceeds $40 \%$ [1-3]. The prevalence of hypertension in the World Health Organisation (WHO)European region has been reduced since 1980 and now

*Address correspondence to this author at the Department of Physiotherapy, Technological Educational Institution (TEI) of Athens, Greece;

Tel: +306942408757; E-mail: papathanasiou.g@gmail.com averages about $30 \%$, with noticeable differences in average BP levels across countries [4]. An elevated BP is an important risk factor for premature disability and mortality and contributes to the burden of heart disease, stroke and kidney failure [5].

Overweight, smoking and physical inactivity, important non-communicable diseases, are strongly related to a deterioration in overall health status and are among the most important modifiable risk factors for chronic disease and premature death [6]. Modifications of these lifestyle risk factors, such as increased exercise levels and lower body weight, have been shown to significantly decrease BP levels and hypertension rates [5,7].

In Greece, the prevalence of hypertension ranges, depending on the study, between $31 \%$ and $40 \%$ [8,9], rates of 
physical inactivity and abstention from exercise are at a record high among European Union (EU) members [10], while the country suffers from an enormous smoking-related public health problem, having the highest proportion of smokers $(42 \%)$ in the EU [11]. In addition, data show that $35.2 \%$ of Greek adults are overweight and $22.5 \%$ obese [12], and subsequent research confirms these numbers [13]. It has been shown that the presence of increased body mass index (BMI), high smoking prevalence and high physical inactivity rates in youth may have an adverse effect on middle-aged adult BP, increasing the likelihood of hypertension and related cardiovascular complications later in life [14]. Although many studies have examined the association between lifestyle risk factors and high BP in children, adolescents and the middle-aged population, data for young adults are limited. Therefore, the connection between BP and the aforementioned modifiable lifestyle risk factors needs further examination, since it is of critical importance to public health, not only in Greece, but in many other countries that have a largely smoking, obese and sedentary population.

The objective of the present study was to investigate the associations between BMI, smoking, physical activity (PA) status, and the prevalence of hypertension in healthy Greek young adults.

\section{MATERIALS AND METHODOLOGY}

\section{Study Population}

Two higher education institutes participated in this multicentre cross-sectional study. Data collection took place from March 2009 to June 2013. The subjects were randomly selected from a target population of health science students from the Medical School of Ioannina University and the Physiotherapy Department of the Technological Educational Institute (TEI) of Athens. A self-addressed questionnaire and the Greek version of the short International Physical Activity Questionnaire (IPAQ-Gr) were given to 1500 students in order to record demographic data, health-related information, smoking behaviour, and PA status. The study protocol, all questionnaire administration procedures, BMI and BP measurements were standardised at the beginning of the study. All healthy young adults aged 19-30 years old were eligible to participate. Other inclusion criteria included health status, which was assessed by the physician team of the research group. All subjects with medical comorbidities, or health-related problems that might have interfered with their BP or their ability to participate in PAs (recent musculoskeletal injuries, pregnancy or period in women, metabolic disease, current illness, use of any medication, alcohol or drug abuse) were excluded. Written informed consent was obtained from all participants. The participation rate was high $(83.3 \%)$, even though no incentives were offered. Of the 251 students excluded, 79 reported healthrelated problems, 146 returned questionnaires with missing data and 26 refused to participate. The final cohort size of the study was 1249 students (522 men) (Table 1). The study protocol was approved by the research committee of the TEI of Athens (February $16^{\text {th }}, 2010$ ) and followed the principles of the Helsinki Declaration and its later amendments.

\section{Smoking Behaviour}

Subjects were classified as current smokers (smoking during the last 30 days), ex-smokers (given up smoking more than one month before), or non-smokers (never smoked). Current smokers were classified into three ordered smoking volume sub-categories, depending on the daily number of cigarettes (cig/d) smoked: (1) 0-10 cig/d, light smokers; (2) $11-20 \mathrm{cig} / \mathrm{d}$, moderate smokers; (3) $\geq 21 \mathrm{cig} / \mathrm{d}$, heavy smokers. The very small number of occasional smokers was grouped with current smokers in sub-category 1 (0-10 cig/d).

\section{Physical Activity Assessment}

The PA status of the subjects was evaluated using the IPAQ-Gr instrument, which has shown good to high reliability [15] and adequate validity [16] in young adults. Briefly, the purpose of this instrument is to sum up vigorous, moderate and walking PAs over the previous seven-day period and generate a total physical activity score $\left(\mathrm{PA}_{\mathrm{score}}\right)$, expressed in MET-minutes per week (MET'min'wk $\left.{ }^{-1}\right)$. Based on the IPAQ scoring procedure [15], PA status was classified into three categories $\left(\mathrm{PA}_{\text {classes }}\right)$ : (1) low $\mathrm{PA}_{\text {class, }}$ insufficiently active subjects (total $\mathrm{PA}_{\text {score }}<600 \mathrm{MET} \cdot \min \cdot \mathrm{wk}^{-\mathbf{1}}$ ); (2) moderate $\mathrm{PA}_{\text {class }}$; and (3) high $\mathrm{PA}_{\text {class }}$ (total $\mathrm{PA}_{\text {score }} \geq 3000$ MET'min ${ }^{*} k^{-1}$ or vigorous $\left.\mathrm{PA}_{\text {score }} \geq 1500 \mathrm{MET}^{\cdot} \min ^{*} \mathrm{wk}^{\mathbf{- 1}}\right)$. In addition, the prevalence of high vs. low vigorous PA was recorded and the cut-off point was set at $1500 \mathrm{MET}^{\cdot} \mathrm{min}^{\cdot} \mathrm{wk}^{-1}$.

\section{Body Mass Index and Blood Pressure Measurements}

BMI, a well-established measure of obesity [17], was calculated as weight in kilograms divided by the square of height in metres. BMI was categorised according to the WHO criteria for normal, overweight and obese, defined as under-weight $\quad\left(\mathrm{BMI}<18.5 \quad \mathrm{~kg} / \mathrm{m}^{2}\right), \quad$ normal weight $\left(18.5 \leq \mathrm{BMI}<25 \mathrm{~kg} / \mathrm{m}^{2}\right)$, overweight $\left(25 \leq \mathrm{BMI}<30 \mathrm{~kg} / \mathrm{m}^{2}\right)$, and obese $\left(B M I \geq 30 \mathrm{~kg} / \mathrm{m}^{2}\right)$ to assess clinically applicable cut points. Height was measured (to two decimal places) using standard height meters, with the participant standing upright. Weight was measured using a calibrated weighing scale, with the participant wearing no shoes and lightly clothed.

The BP was measured using a standard mercury sphygmomanometer with the participant in a seated position, after 10 min of rest [5]. Three BP measurements were taken, at least 3 minutes apart. The mean of the second and the third measurements was calculated to represent participants' BP. The blood pressure classification was based on the new guidelines of the European Society of Hypertension and European Society of Cardiology [5]. Hypertensives (Grade I, II and III) were defined as those with systolic BP (SBP) $\geq 140 \mathrm{mmHg}$ and/or diastolic BP (DBP) $\geq 90 \mathrm{mmHg}$. Further, high normal BP was defined as having an average SBP between 130-139 $\mathrm{mmHg}$ and an average DBP between 85 $89 \mathrm{mmHg}$. 
Table 1. Personal characteristics, blood pressure measurements and classification, body mass index, smoking behaviour and physical activity status of study population.

\begin{tabular}{|c|c|c|c|c|}
\hline & Total Group $(\mathrm{n}=1249)$ & Males $(n=522)$ & Females $(\mathrm{n}=727)$ & $p$ value $^{\mathrm{a}}$ \\
\hline Height (m) & $1.71 \pm 0.09$ & $1.79 \pm 0.07$ & $1.66 \pm 0.06$ & $<0.001$ \\
\hline BMI $\left(\mathrm{kg} / \mathrm{m}^{2}\right)$ & $22.7 \pm 3.1$ & $24.2 \pm 2.8$ & $21.7 \pm 2.9$ & $<0.001$ \\
\hline Systolic BP (mmHg) & $123.8 \pm 12.6$ & $129.2 \pm 12.1$ & $119.9 \pm 11.4$ & $<0.001$ \\
\hline Diastolic BP (mmHg) & $74.9 \pm 9.2$ & $77.0 \pm 9.1$ & $73.4 \pm 9.1$ & $<0.001$ \\
\hline \multicolumn{5}{|l|}{ BP classification } \\
\hline Optimal (\%) & 35.6 & 17.4 & 48.7 & 0.000 \\
\hline Grade I HT (\%) & 12.1 & 18.6 & 7.3 & $<0.001$ \\
\hline Grade II HT (\%) & 1.0 & 2.1 & 0.3 & 0.002 \\
\hline \multicolumn{5}{|l|}{ BMI class } \\
\hline Underweight (\%) & 5.0 & 0.4 & 8.4 & $<0.001$ \\
\hline Normal-weight (\%) & 74.9 & 69.0 & 79.1 & $<0.001$ \\
\hline Overweight (\%) & 17.0 & 26.1 & 10.5 & $<0.001$ \\
\hline Obese $(\%)$ & 3.1 & 4.6 & 2.1 & 0.012 \\
\hline \multicolumn{5}{|l|}{ PA Status } \\
\hline Total $\mathrm{PA}_{\text {score }}$ & $1248 / 786(330-1697)$ & 1420/861(394-1929) & $1132 / 714(311-1493)$ & 0.004 \\
\hline Vigorous $\mathrm{PA}_{\text {score }}$ & $576 / 0(0-720)$ & $796 / 0(0-1200)$ & $426 / 0(0-480)$ & $<0.001$ \\
\hline Moderate $\mathrm{PA}_{\text {score }}$ & $277 / 120(0-360)$ & $288 / 120(0-360)$ & $270 / 120(0-400)$ & NS \\
\hline Walking $\mathrm{PA}_{\text {score }}$ & $400 / 264(132-495)$ & $342 / 231(99-462)$ & 439/297(149-495) & $<0.001$ \\
\hline Low PA (\%) & 42.8 & 40.6 & 44.4 & NS \\
\hline Moderate PA $(\%)$ & 43.2 & 40.6 & 45.0 & NS \\
\hline High PA $(\%)$ & 14.0 & 18.8 & 10.6 & $<0.001$ \\
\hline
\end{tabular}

BMI: body mass index; HT: hypertension; NS: non-significant; PA: physical activity. Age, BMI and smoking years are expressed as mean \pm SD. PA ${ }_{\text {scores }}$ are expressed as mean/median and (25th-75th percentiles). Smoking prevalence is expressed as percentage of current smokers. ${ }^{a}$ comparisons between males and females; ${ }^{\mathbf{b}}$ in 515 participants; ${ }^{\mathbf{c}}$ comparison of the prevalence of heavy smoking between sexes.

\section{Statistical Analysis}

Statistical analysis of the data was performed using the SPSS v.19 software package (IBM ${ }^{\circledR}$ SPSS $^{\circledR}$ Statistics, IBM Corp.) and STATGRAPHICS Plus v.5.1 Enterprise Edition (Statistical Graphics Corp). Age and BMI values were normally distributed (Kolmogorov-Smirnov test) and are presented as mean \pm standard deviation. IPAQ-Gr PA $\mathrm{A}_{\text {scores }}$ were skewed and are presented as mean/median and $25^{\text {th }}-75^{\text {th }}$ percentile values. Analysis of variance for anthropometric indices and the Mann-Whitney $U$ test for non-parametric 
continuous (i.e. $\mathrm{PA}_{\text {scores }}$ ) or chi-square for non-parametric categorical (i.e. $\mathrm{PA}_{\text {class }}$ ) data were used to examine $\mathrm{BP}$ differences between sexes and between sub-population groups. Estimated population proportions, weighted for group sizes, were used to search for possible significant differences in the prevalence of hypertension between subpopulation groups. Multivariable linear regression analysis was used to further investigate the cross-sectional association between lifestyle risk factors and changes in SBP and DBP. The models included age, BMI, smoking, $\mathrm{PA}_{\text {class, }}$, total PA, vigorous PA, moderate PA and walking as factors (independent variables), and SBP and DBP as the dependent variables. Stepwise linear regression was then applied to determine the best variable model. Finally, logistic regression was implemented to investigate the association between lifestyle risk factors and hypertension ( $\mathrm{BP} \geq 140 / 90$ $\mathrm{mmHg}$, dependent categorical variable). Adjusted odds ratios (ORs) with $95 \%$ confidence intervals (CI) were computed to describe differences in hypertension prevalence between sup-population groups. The level of significance in all analyses was set as a $p$-value less than 0.05 .

\section{RESULTS}

\section{Descriptives}

One thousand, two hundred and forty-nine young healthy adults (522 men) with a mean age of 21.8 years participated in the present study (Table 1). About $17 \%$ of the overall population were classified as overweight and $3 \%$ as obese (Table 1). Significantly more females were classified as underweight, whereas the prevalence of overweight and obesity was significantly higher in males. In the total population, smoking prevalence was $35.2 \%$. Light smokers accounted for $47.2 \%$ of the smoking population, whereas $15.3 \%$ were heavy smokers (Table 1). Smoking prevalence was slightly greater, though not statistically significantly so, in males compared to females. Based on the IPAQ classification criteria, $42.8 \%$ of the total population was insufficiently active (Table 1). On the other hand, only $14.0 \%$ of the participants were classified as highly active subjects. Males were found to be more physically active than females. Total and vigorous $\mathrm{PA}_{\text {scores }}$ were significantly higher for male subjects.

\section{Sex and Blood Pressure}

About $13 \%$ of the total population were classified as hypertensives, and $17.7 \%$ had high normal BP (Table 1). Males had significantly higher SBP and DBP values than females $(129.2 / 77.0$ vs. $119.9 / 73.4 \mathrm{mmHg}, p<0.001)$. Males were 1.9 times more likely to be hypertensive $(\mathrm{OR}=1.87$; 95\%CI: 1.26-2.76) than females. The prevalence of both high-normal BP (24.5\% vs. $12.8 \%)$ and hypertension $(20.7 \%$ vs. $7.6 \%$ ) was significantly higher for male participants. In all analyses, sex was a strongly significant confounder in the association of lifestyle risk factors with SBP/DBP levels (multivariable linear regression) and hypertension (multinomial logistic regression). For this reason, all subsequent data analyses were stratified per sex.

\section{Body Mass Index and Blood Pressure}

In the overall population, the prevalence of hypertension was impressively higher in overweight $(32.5 \%)$ and obese participants $(64.1 \%)$ compared to normal-weight subjects (7.3\%). In both sexes, overweight and obese participants had a significantly higher prevalence of hypertension (Table 2) and higher SBP/DBP levels compared to normal-weight subjects (Tables 3-4). In all analyses, BMI, both as a continuous and as a categorical variable $\left(\mathrm{BMI}_{\text {class }}\right)$, was found to be the only significant independent predictor for the difference in SBP/DBP measurements (linear regression, Tables 5-6) and for the prevalence of hypertension (logistic regression, Table 7) among the lifestyle risk factors examined. An increase of $1 \mathrm{BMI}$ unit was associated with, on average, a $2.0 \mathrm{mmHg}(1.4 \mathrm{mmHg})$ and a $1.3 \mathrm{mmHg}(0.8$ $\mathrm{mmHg}$ ) increase in SBP and DBP in males (females), respectively. In the overall population, overweight $\left(\mathrm{OR}=4.71 ; 95 \% \mathrm{CI}: 3.17-7.00\right.$, adjusted for sex and $\left.\mathrm{TPA}_{\text {score }}\right)$ and obese participants $(\mathrm{OR}=18.06$; 95\%CI: 8.81-37.03, adjusted for sex and $\mathrm{TPA}_{\text {score }}$ ) were more likely to be hypertensives compared to normal-weight subjects.

\section{Physical Activity and Blood Pressure}

When PA was examined as an independent categorical variable $\left(\mathrm{PA}_{\text {class }}\right)$, non-significant differences in the prevalence of hypertension (Table 2) and in SBP/DBP levels (Tables 3-4) were found between participants with high and those with low $\mathrm{PA}_{\text {class, }}$ in both sexes. However, by linear regression analysis, continuous vigorous $\mathrm{PA}_{\text {score }}$ was found to be significantly and directly associated with SBP, but only in men. Total PA was excluded from the models for reasons of multicollinearity. Indeed, male participants with high vigorous $\mathrm{PA}_{\text {score }}$ (vigorous $\mathrm{PA}_{\text {score }} \geq 1500 \mathrm{MET} \cdot \mathrm{Min}^{*} \mathrm{wk}^{-1}$ ) had a significantly higher prevalence of hypertension $(34.5 \%$ vs. 21.5\%, $p=0.011$; Table 2) and SBP level (132.4 vs. 129.4 $\mathrm{mmHg}, p=0.049$; Table 3) compared with those men with a low vigorous $\mathrm{PA}_{\text {score }}$ Logistic regression showed that male participants with a high vigorous $\mathrm{PA}_{\text {score }}$ were 2.26 times more likely to be hypertensives compared with those having a low vigorous $\mathrm{PA}_{\text {score }}$ (Table 7).

\section{Smoking and Blood Pressure}

Smoking was not associated with BP in any of the analyses and models examined. The prevalence of hypertension was not significantly different, whereas nonsignificant differences in SBP/DBP values were found between smokers and non-smokers in both sexes (Tables 24). Regression analyses indicated that, in both sexes, smoking was not a significant predictor of either differences in SBP/DBP (Tables 5-6) or hypertension prevalence (Table 7). Finally, in the overall population, smokers were 0.66 times less likely to be hypertensives compared to nonsmokers, but not significantly so (OR=0.66; 95\%CI: $0.44-$ $0.99 ; p=0.05$, adjusted for age, sex, BMI and $\left.\mathrm{TPA}_{\text {score }}\right)$.

\section{DISCUSSION}

In the present study, BMI was the main predictor of high BP levels, being strongly and directly associated with hypertension rates in both male and female young adults. 
Table 2. Differences in the prevalence of hypertension between sub-population groups.

\begin{tabular}{|c|c|c|c|}
\hline Risk factor & & Prevalence of HT (\%) & $p$ value ${ }^{\mathrm{a}}$ \\
\hline \multirow{3}{*}{ BMI } & Normal weight & 11.9 & \\
\hline & Overweight & 36.0 & $<0.001$ \\
\hline & Normal weight & 11.9 & \\
\hline \multirow{2}{*}{ Smoking } & Non-smokers & 20.8 & \\
\hline & Current smokers & 19.9 & NS (0.78) \\
\hline \multirow{2}{*}{$\mathrm{PA}$} & Low PA class & 19.8 & \\
\hline & High PA class & 24.5 & NS (0.35) \\
\hline \multicolumn{4}{|c|}{ Females $(n=727)$} \\
\hline \multirow{4}{*}{ BMI } & Normal weight & 4.3 & \\
\hline & Overweight & 26.3 & $<0.001$ \\
\hline & Normal weight & 4.3 & \\
\hline & Obese & 60.0 & $<0.001$ \\
\hline \multirow{2}{*}{ Smoking } & Non-smokers & 8.8 & \\
\hline & Current smokers & 5.2 & NS (0.08) \\
\hline
\end{tabular}

BMI: body mass index; HT: hypertension; NS: non-significant;

PA: physical activity.

acomparisons between overweight vs. normal weight, obese vs. normal-weight, smokers vs. non-smokers, high PA vs. low PA and high vigorous PA vs. low vigorous PA weighted for group sizes.

${ }^{\mathbf{b}}$ The cut-off point for low vs. high vigorous PA was set at 1500 MET'min'wk $^{-1}$ of vigorous PA.

Although smoking prevalence and the rates of low PA were well above EU youth averages, neither smoking nor PA status was associated with BP levels and hypertension rates in this sample of young adults. Finally, male sex was a strong predictor of an elevated resting BP.

\section{Descriptives}

The prevalence of hypertension found in our target population is in line with that of Psaltopoulou et al, where $15.3 \%$ of the participants (aged 25-44 years) were classified as hypertensives [9]. It is difficult to compare our results with those of other European countries, because data from the EU concerning young adults are scarce. Compared to recent data for young adults in the USA [18], our participants had an impressively lower prevalence of hypertension $(13 \%$ vs. $24.4 \%$ ). This may be attributed to the cardioprotective effects of the Mediterranean diet on endothelial function and
BMI levels, benefits that affect BP and have been adequately documented before $[19,20]$.

\section{BMI and Blood Pressure}

Overweight and obesity are the fifth leading risk factor for death, and have become a severe worldwide pandemic whose prevalence has nearly doubled since 1980 [21]. According to the WHO, 35\% of adults aged 20 years and over were overweight in 2008, and around $12 \%$ were obese [21]. In 2008, over $50 \%$ of both men and women in the WHO European region were overweight, and roughly $23 \%$ of women and $20 \%$ of men were obese [22]. Excess body weight and obesity are serious public health threats, as they significantly increase the risk of chronic diseases such as cardiovascular disease, type-2 diabetes mellitus, hypertension, coronary heart disease, osteoarthritis, and certain types of cancer [17]. The relationship between overweight/obesity and hypertension has long been 
investigated, with the risk of hypertension being up to five times higher among obese people than among those of normal weight [17]. In addition, a large number of studies have concluded that there is a strong and independent positive correlation between increased BMI and office or ambulatory BP [23, 24].

The prevalence of overweight/obesity found in the present study is comparable with the data for young adults in Great Britain [25] (overweight $=15.4 \%$; obese $=4.0 \%$ ), but these rates are much lower compared to young adults in other countries, such as Cyprus [26] and Germany [27]. Our results agree with those of numerous other studies showing that BMI and BP levels are positively correlated, in both sexes and in all ages [17, 23, 24].
While the relationship between overweight/obesity and increased BP is well established, the physiological connection between them is not so clear, especially concerning essential hypertension. A number of pathways have been described, with recent research focusing more on the neurohormonal aspect. The interrelation between those mechanisms is in itself an active field of research. Most explanations fall into one of two categories (or both): BP in overweight/obese people is increased either through stimulated activation of the sympathetic nervous system, or via increased sodium retention by the kidneys [28].

- $\quad$ The renin-angiotensin-aldosterone system (RAAS). The RAAS is a feedback mechanism originating in the kidney that, through the activation of angiotensin II,

Table 3. Differences in systolic and diastolic blood pressure values between groups of male participants.

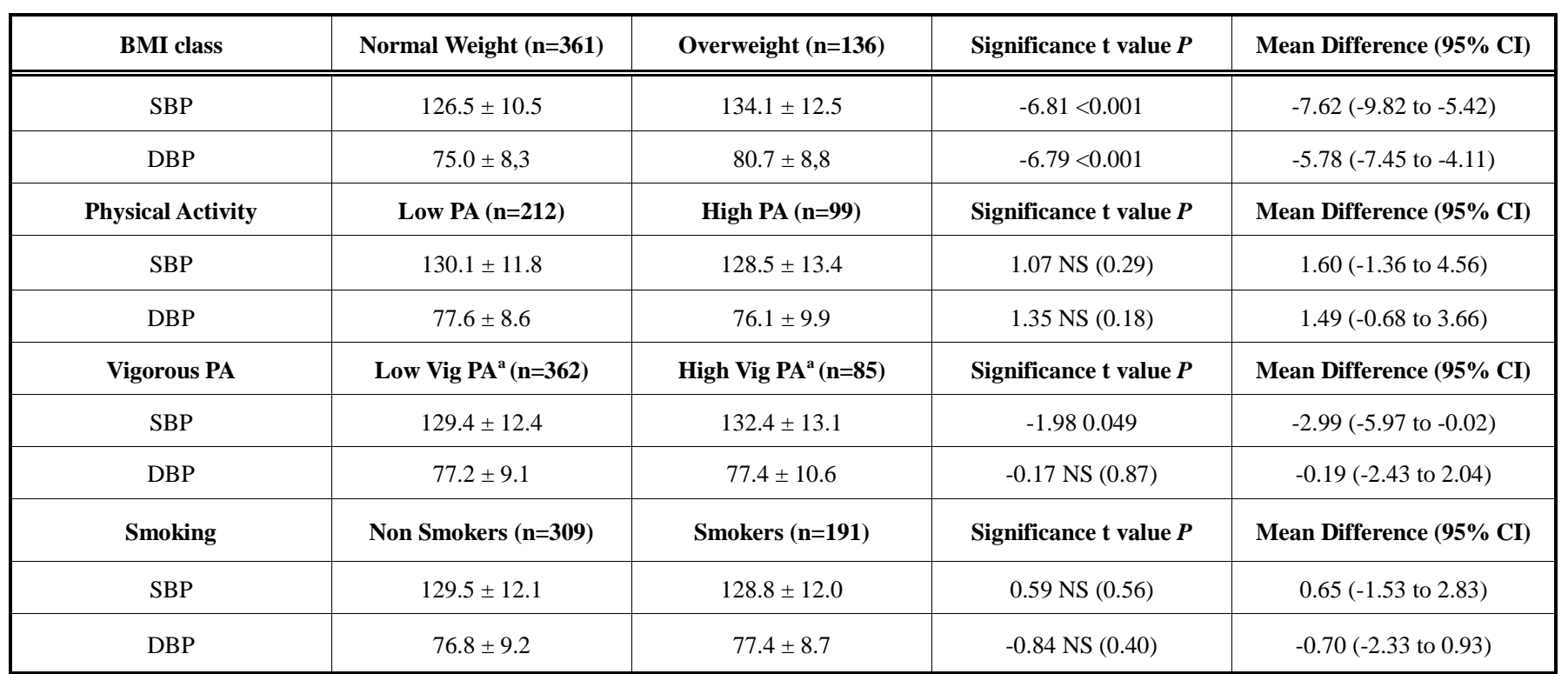

BMI: body mass index; CI: confidence interval; DBP: diastolic blood pressure; NS: non-significant; PA: physical activity; SBP: systolic blood pressure. ${ }^{a}$ the cut-off point for low vs. high vigorous PA was set at 1500 MET min $^{-1} k^{-1}$ of vigorous PA.

Table 4. Differences in systolic and diastolic blood pressure values between groups of female participants.

\begin{tabular}{|c|c|c|c|c|}
\hline BMI class & Normal Weight $(n=578)$ & Overweight (n=75) & Significance t value $P$ & Mean Difference (95\% CI) \\
\hline SBP & $118.9 \pm 10.5$ & $126.6 \pm 13.5$ & $-5.8<0.001$ & $-7.68(-10.3$ to -5.24$)$ \\
\hline DBP & $72.6 \pm 8.6$ & $77.9 \pm 10.8$ & $-4.8<0.001$ & $-5.24(-7.38$ to -3.10$)$ \\
\hline Physical Activity & Low PA $(n=323)$ & High PA $(n=77)$ & Significance t value $P$ & Mean Difference (95\% CI) \\
\hline SBP & $119.9 \pm 11.3$ & $117.6 \pm 11.5$ & $1.63 \mathrm{NS}(0.10)$ & $2.35(-0.48$ to 5.18$)$ \\
\hline DBP & $73.4 \pm 9.2$ & $71.8 \pm 9.8$ & $1.34 \mathrm{NS}(0.18)$ & $1.18(-0.74$ to 3.89$)$ \\
\hline Vigorous PA & Low Vig $P^{a}{ }^{a}(n=609)$ & High Vig $P^{a}(n=52)$ & Significance t value $P$ & Mean Difference (95\% CI) \\
\hline SBP & $120.0 \pm 11.6$ & $120.0 \pm 13.1$ & $-0.01 \mathrm{NS}(0.99)$ & $-0.01(-3.33$ to 3.30$)$ \\
\hline DBP & $73.4 \pm 9.2$ & $73.1 \pm 10.1$ & $0.29 \mathrm{NS}(0.77)$ & $0.39(-2.24$ to 3.01$)$ \\
\hline Smoking & Non Smokers $(n=446)$ & Smokers $(n=249)$ & Significance t value $P$ & Mean Difference (95\% CI) \\
\hline SBP & $120.1 \pm 12.0$ & $119.4 \pm 10.0$ & $0.74 \mathrm{NS}(0.46)$ & 0.66 (-1.10 to 2.42$)$ \\
\hline DBP & $73.1 \pm 9.2$ & $74.0 \pm 8.5$ & $-1.18 \mathrm{NS}(0.24)$ & $-0.84(-2.23$ to 0.56$)$ \\
\hline
\end{tabular}

BMI: body mass index; CI: confidence interval; DBP: diastolic blood pressure; NS: non-significant; PA: physical activity; SBP: systolic blood pressure.

${ }^{a}$ the cut-off point for low vs. high vigorous PA was set at 1500 MET min $^{*} \mathrm{k}^{-1}$ of vigorous PA. 
Table 5. Linear regression model for the association between life style risk factors and change in systolic blood pressure.

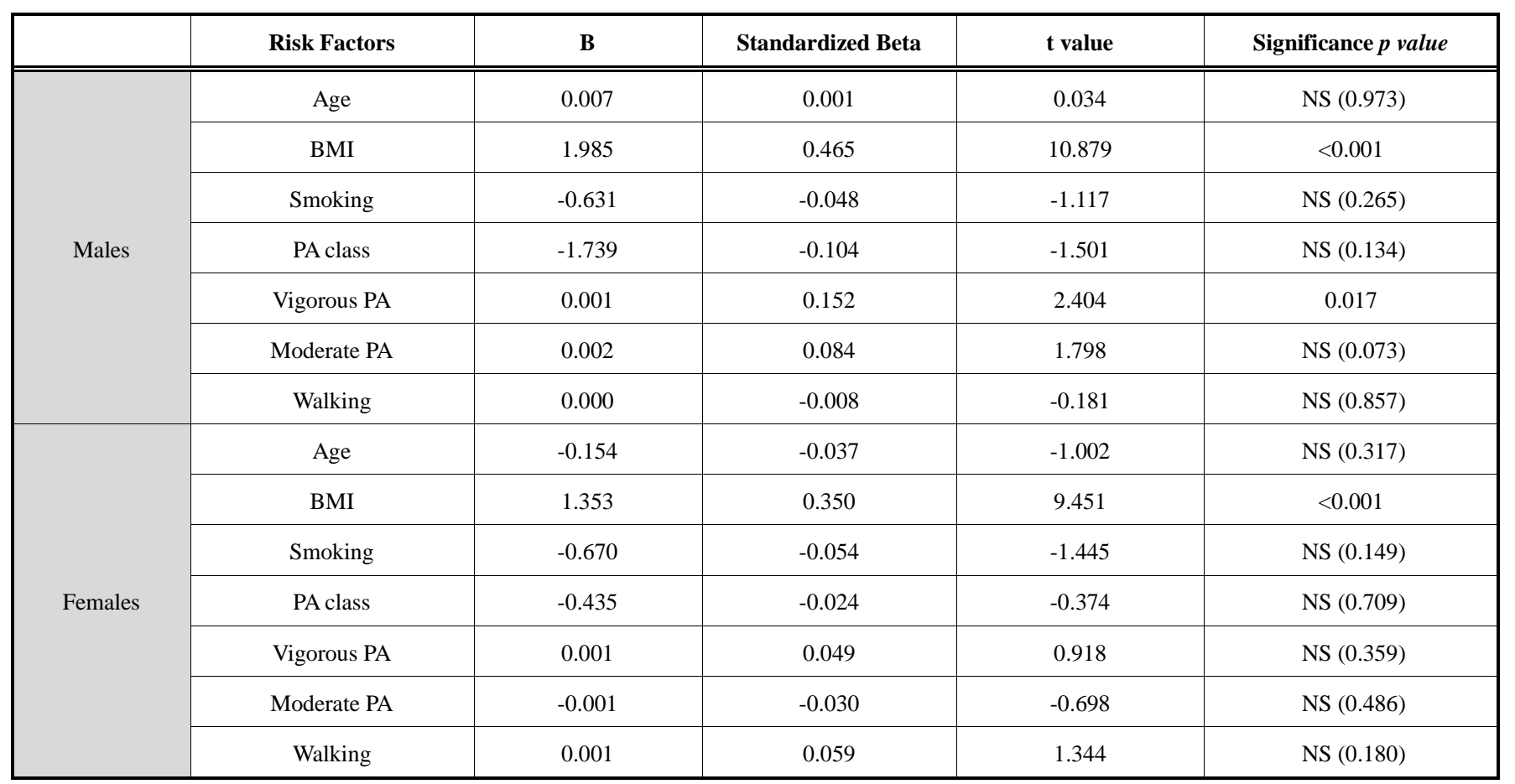

BMI: body mass index; NS: non-significant; PA: physical activity;

In stepwise regression, only BMI and vigorous PA (and BMI for females) were included in the final model. TPA score was excluded due to multicollinearity.

helps elevate BP to normal levels when it drops (e.g. as a result of bleeding). It has been shown that, as BMI and fat tissue increase, so does the volume of circulating angiotensin [29, 30]. Angiotensin II has both a shortand a long-term action in increasing BP levels. In the short term it acts rapidly as a powerful vasoconstrictor, and over the course of days or weeks it raises BP through decreased salt excretion from the kidneys, therefore increasing fluid volume [28].

- Free fatty acids (FFAs). FFA concentration is undeniably higher in the overweight and obese individual since they arise from adipose tissue [31,32]. There are a number of pathophysiological pathways that correlate elevated FFAs with hypertension, including acute and chronic insulin resistance, increased sympathetic activity due to oxidative stress, interference with NO-induced vasodilation, and more $[31,33]$.

- Insulin resistance and hyperinsulinaemia. Lowered insulin sensitivity is a characteristic feature of essential hypertension. Insulin has important effects on cardiovascular as well as muscle tissue. It causes vasodilation through increased NO production and a reduction in vascular smooth muscle cells; thus, any reduction in the functionality of the peptide will obviously have adverse effects on blood pressure [28]. Additionally, insulin resistance causes increased blood flow to skeletal muscles to compensate for the reduced glucose delivery, which in turn also increases BP [34]. Finally, it contributes to increased sympathetic nervous system activity in different tissues, most importantly the kidney, resulting in sodium retention, a major factor in the control of BP [35].
- Leptin. Leptin is another peptide that affects blood pressure levels. As a hormone derived from fatty tissue, its circulating levels are directly connected to obesity. Its primary role is to control appetite by inducing the feeling of satiety and by increasing sympathetic outflow [36]. Although obese individuals appear resistant to the former effect of leptin, the increased sympathetic activity persists, contributing to their increased BP [37].

- $\quad$ Obstructive sleep apnoea. Obstructive sleep apnoea is a condition characterised by frequent collapse of the upper airway during sleep, causing cessation of airflow followed by a decline in oxygen saturation. It is significantly more prevalent among overweight, and especially obese individuals [38]. The resulting physiological reaction includes sympathetic activation, increased blood viscosity, oxidative stress, and inflammation, conditions that are all contributing factors to elevated BP $[39,40]$.

\section{Physical Activity and Blood Pressure}

Although a plethora of epidemiological studies have underscored the importance and effectiveness of PA and exercise, the prevalence of physical inactivity is increasing worldwide, to the extent that it has become a substantial public health concern and a considerable economic burden [41, 42]. Low levels of PA are inversely related with cardiovascular morbidity, and are strong prognostic indexes of mortality, with 1.9 million deaths per year being attributed to this cause $[42,43]$.

Concerning PA levels, our results place Greek young adults at a level below the EU averages [44]. Our findings 
Table 6. Linear regression model for the association between life style risk factors and change in diastolic blood pressure.

\begin{tabular}{|c|c|c|c|c|c|}
\hline & Risk Factors & $\mathbf{B}$ & Standardized beta & t value & Significance $p$ value \\
\hline \multirow{5}{*}{ Males } & Age & 0.373 & 0.111 & 2.516 & 0.012 \\
\hline & Smoking & 0.242 & 0.025 & 0.559 & NS (0.576) \\
\hline & PA class & -0.935 & -0.075 & -1.056 & NS $(0.292)$ \\
\hline & Moderate PA & 0.000 & 0.003 & 0.070 & NS (0.944) \\
\hline & Walking & 0.001 & 0.047 & 1.038 & NS $(0.300)$ \\
\hline \multirow{4}{*}{ Females } & Age & 0.086 & 0.026 & 0.689 & NS $(0.491)$ \\
\hline & Vigorous PA & 0.001 & 0.053 & 0.984 & NS $(0.326)$ \\
\hline & Moderate PA & 0.000 & 0.019 & 0.433 & NS $(0.665)$ \\
\hline & Walking & 0.002 & 0.102 & 2.270 & 0.024 \\
\hline
\end{tabular}

BMI: body mass index; NS: non-significant; PA: physical activity;

In stepwise regression, only BMI and age (BMI and walking for females) were included in the final model. TPA score was excluded due to multicollinearity.

are comparable with those of others who reported high rates $(>45 \%)$ of low PA [45] or physical inactivity [46,47] among Greek university students. Regarding the sex-related differences, the present data are in line with other reports, inasmuch as young men tend to be more physically active than young women $[9,47]$.

When the effects of PA on resting haemodynamic factors are examined, most studies agree that PA-moderate or intensive - is significantly associated with a lower heart rate [48]. However, findings regarding the PA-BP relationship are conflicting. There is ample evidence for a significant inverse association between PA and BP levels [49, 50], and participating in PAs has been found to delay the development of hypertension [5,7]. In addition, lower $\mathrm{BP}$ readings have been found among normotensive individuals with higher IPAQ-measured PA [51]. Most authors note that the effect of $\mathrm{PA}$ on $\mathrm{BP}$ may be due to a reduction in total peripheral resistance and an improvement in endothelial function [5, 7]. On the other hand, in the present study, categorical PA class was associated with neither BP levels nor the prevalence of hypertension in either sex. This is consistent with other findings indicating that PA status may not be a significant predictor of high BP and/or the prevalence of hypertension [52-54]. Gaya et al reported that, when cardiorespiratory fitness and BMI were included in their analyses as confounders, sports competition PAs were not associated with BP levels [55].

To explain the discrepancies between these findings, it is important to keep in mind that the BP decrease seen in a lot of PA-related studies might be attributable to modification of other examined risk factors, such as reduction of body weight and changes in dietary intake, which have been found to be strong predictors of high BP levels and the development of hypertension [56]. In addition, the association between PA and BP seen in other studies may be the result of general fitness, rather than the PA itself [52]. For example, Carnethon et al. underline that these significant health-related PA-BP negative correlations are seen only in highly fit individuals [57]. The conflicting results presented by those PA-BP studies that assess PA through self-reported questionnaires as a surrogate of physical fitness-which indeed is unquestionably a strong factor in BP lowering [5,7] and a cornerstone therapy for the prevention and control of hypertension [56,58] — once again highlight the controversial relation, in terms of validity [59], between physical fitness and PA [60].

Another important finding of the present study was that, in men, continuous vigorous $\mathrm{PA}_{\text {score }}$ was directly related with SBP levels and the prevalence of hypertension. Men with a high vigorous $\mathrm{PA}_{\text {score }}\left(\geq 1500\right.$ MET'min $\left.w^{-\mathbf{1}}\right)$ had significantly higher SBP levels and higher hypertension prevalence rates. Similar results in both sexes have reported by Tsioufis et al. [61], where increased PA was significantly associated with higher SBP levels. Our findings may be partially explained by the fact that men had a significantly higher BMI, the main predictor of high BP in our study. Another factor may be that physically active young menlike our male participants with a high vigorous $\mathrm{PA}_{\text {score }}$-are more likely to be involved in vigorous PAs, such as strength training or intense sports activities, than are women 
Table 7. Logistic regression and adjusted odds ratios for the association between life style risk factors and hypertension.

\begin{tabular}{|c|c|c|c|c|}
\hline \multicolumn{2}{|c|}{ Risk Factor } & B & p value & ORs $(95 \%$ CI $)$ \\
\hline \multirow{2}{*}{ BMI } & Overweight & 1.358 & $<0.001$ & $3.89(2.36-6.40)$ \\
\hline & Normal weight & $0^{*}$ & & 1.00 \\
\hline \multirow{2}{*}{ Smoking } & Non-smokers & $0^{*}$ & & 1.00 \\
\hline & Current smokers & -0.207 & NS & $0.81(0.49-1.36)$ \\
\hline $\mathrm{PA}$ & Low PA class & $0^{*}$ & & 1.00 \\
\hline \multicolumn{5}{|c|}{ Females } \\
\hline \multirow{4}{*}{ BMI } & Normal weight & 0 & & 1.00 \\
\hline & Overweight & 2.025 & $<0.000$ & $7.58(3.91-14.67)$ \\
\hline & Normal weight & $0^{*}$ & & 1.00 \\
\hline & Obese & 3.704 & $<0.001$ & $40.62(12.16-135.7)$ \\
\hline \multirow{2}{*}{ Smoking } & Non-smokers & $0^{*}$ & & 1.00 \\
\hline & Current smokers & -0.713 & NS & $0.49(0.24-0.99)$ \\
\hline
\end{tabular}

BMI: body mass index; NS: non-significant; PA: physical activity;

In LR analysis, low PA class for physical activity, non-smokers for smoking, normal weight for BMI and normal BP for hypertension were set as the reference categories. Odds ratios > 1.0 indicate that overweight and obese of both sexes and men with high vigorous PA are more likely to be hypertensive than normalweight participants and men with low vigorous PA respectively. Odds ratios $<1.0$ indicate that smokers are less likely to be hypertensive than non-smokers.

* this parameter is set to zero because it is redundant.

a the cut-off point for low vs. high vigorous PA was set at $1500 \mathrm{MET}^{-m i n} \mathrm{wk}^{-1}$ of vigorous PA.

[51,62,63]. Although data regarding the association of vigorous PA and intense exercise with BP levels are limited [7], it could be argued that regular participation in these types of activity, which have a strong isometric component and an acute strong BP raising effect [64], may be connected with the higher BP levels found in our vigorously active male study population.

\section{Smoking and Blood Pressure}

Smoking is a major risk factor for cardiovascular morbidity and mortality, and is considered to be the leading preventable cause of death in the world, causing $25 \%$ of deaths from cardiovascular disease in the middle-aged population [65]. Our findings indicated a pattern of smoking prevalence $(35.1 \%)$ in Greek young adults that was comparable with European youth smoking rates (35\%), in line with previously published data for Greek young adults [66].

In contrast to the adequately documented direct association between overweight and BP, the relationship between smoking and BP is not clear. According to Green et al, most epidemiological studies up to 1985 concluded that smokers had a lower resting SBP than non-smokers [67]. Similar data were published during the following years $[68,69]$. On the other hand, our results indicated that there were no significant differences in resting SBP and DBP between young smokers and non-smokers, in line with many studies showing that there were no significant associations between resting BP and smoking in young people $[70,71]$ or 
in adults $[72,73]$. To add to the controversy, smokers have been found to have higher aortic SBP [74] or brachial SBP at rest $[71,75]$.

Adaptation mechanisms and the biochemical or haemodynamic effects of chronic smoking, such as the chronic effect of cotinine on vascular smooth muscle fibres [76], or the nicotine sympathetic pressor effect [76,77], may explain the lower BP that many have found in smokers. has also been noted that chronic smoking induces selective changes in autonomic cardiac control during standing, differentiates the responses of the autonomic nervous system to excitatory stimuli, and blunts the posture reactions of the circulatory system $[77,78,79]$. Thus, a paradoxical lower BP measured in a sitting position in smokers can probably be explained [79]. On the other hand, if this is the case, it is difficult to explain the results of numerous studies that either did not find significant differences in resting BP between smokers and non-smokers, or indicated that smokers had a higher BP in a sitting position. Differences in the study methodologies, such as the heterogeneity and size of the sample, measurement techniques, matching for confounding variables, etc., may explain the conflict between the published results $[67,70,74]$. For instance, in most studies, BP is obtained at rest after long abstention from smoking, alcohol and coffee. Thus, the recorded values do not represent the mean ambulatory $\mathrm{BP}$, which is usually higher in smokers during daytime activities $[71,76]$.

\section{Sex and Blood Pressure}

The significant sex-BP association found in the present study may be partially explained by the fact that our young men had higher BMI levels and were also reported to be significantly more vigorously active-both factors being independently related with BP levels. Indeed, as has been reported in previous studies, young men tend to participate more in intense sports activities and strengthening exercise programs compared to young women $[51,63]$.

\section{Strengths and Limitations}

The random selection of the subjects from a well-defined and homogeneous target population, the size of the sample, the high participation rate, and the examination of the relationship between BP and lifestyle risk factors separately for males and females added strength to the results of this study. On the other hand, there are important limitations that have to be mentioned. Certain lifestyle risk factors that may be related with BP changes, such as dietary habits, were not assessed in the present study. BMI was the only measure of overweight used in this study. Although widely accepted, it would be better to combine BMI with the use of other obesity measures, such as waist circumference and lipometry, that would allow variations in fat to be monitored. The short IPAQ, although reliable and sufficiently valid in recording physical activity, is not able to distinguish between different types of vigorous PA, such as intense aerobic training, resistive exercises or weight-lifting, forms of exercise that recruit different haemodynamic pathways and may affect BP in different ways. In addition, it has been suggested that self-reported PA should be used with caution in health prevention studies, since it is only a modest surrogate of physical fitness [59]. Finally, generalisation of our findings from a sample of health science students to all Greek young adults would be ill-advised. Socioeconomic status, smoking years, dietary habits, body weight and PA profile, as well as other factors, might differ from the general population. Therefore, the extent to which the present results could be generalised to a more unselected population cohort is unclear.

\section{CONCLUSION}

According to the findings of this study, sex (male) and body mass index were directly associated with young adults' resting systolic and diastolic BP. Our results add to previously published research that, even in youth, being of normal weight may be a primary lifestyle intervention for lowering BP and preventing hypertension. Future research is needed to examine further the association of smoking and physical activity, as well as other lifestyle risk factors, with BP changes.

\section{LIST OF ABBREVIATIONS}

\begin{tabular}{|c|c|c|}
\hline BMI & $=$ & Body Mass Index \\
\hline $\mathrm{BP}$ & $=$ & Blood Pressure \\
\hline DALYS & $=$ & Disability-Adjusted Life Years \\
\hline DBP & $=$ & Diastolic Blood Pressure \\
\hline EU & $=$ & European Union \\
\hline FFAs & $=$ & Free fatty acids \\
\hline IPAQ-Gr & $=$ & $\begin{array}{l}\text { International Physical } \\
\text { Questionnaire - Greek Version }\end{array}$ \\
\hline MET & $=$ & Metabolic Equivalent of the Task \\
\hline PA & & Physical Activity \\
\hline RAAS & $=$ & renin-angiotensin-aldosterone system \\
\hline SBP & $=$ & Systolic Blood Pressure \\
\hline WHO & $=$ & World Health Organisation \\
\hline
\end{tabular}

\section{CONFLICT OF INTEREST}

The authors confirm that this article content has no conflicts of interest.

\section{ACKNOWLEDGEMENTS}

We acknowledge the contribution of Panagiotis Grivas, (University of Ioannina, Medical School - Physiology Laboratory), Spyridon Papafloratos, Anastasia Mamali and Kaliopi Nikolakopoulou (physical therapists) for their assistance in IPAQ-Gr administration and the collection of the data. The authors would also like to thank Philip Lees, Technical Editor of the Hellenic Journal of Cardiology, for his invaluable editorial assistant with the English text.

\section{REFERENCES}

[1] World Health Organization. Raised blood pressure. Situations and trends. Geneva 2013. Available from: http://www.who.int/gho/ncd/ risk_factors/blood_pressure_prevalence_text/en/ (12 December 2013, date last accessed). 
[2] World Health Organization. A global brief on hypertension. Silent killer, global public health crisis. Geneva 2013. Available from: http://apps.who.int/iris/bitstream/10665/79059/1/WHO_DCO_WH D_2013.2_eng.pdf?ua=1 (16 January 2014, date last accessed).

[3] Chow CK, Teo KK, Rangarajan S, et al. Prevalence, awareness, treatment, and control of hypertension in rural and urban communities in high-, middle-, and low-income countries. JAMA 2013; 310(9): 959-68.

[4] World Health Organization. World health statistics. A snapshot of global health. Geneva 2012. Available from: http://apps.who.int/iris/bitstream/10665/70889/1/WHO_IER_HSI_ 12.1_eng.pdf?ua=1 (16 January 2014, date last accessed).

[5] Mancia G, Fagard R, Narkiewicz K, et al. 2013 ESH/ESC guidelines for the management of arterial hypertension: the Task Force for the Management of Arterial Hypertension of the European Society of Hypertension (ESH) and of the European Society of Cardiology (ESC). Eur Heart J 2013; 34(28): 2159-219.

[6] Strong K, Mathers C, Leeder S, Beaglehole R. Preventing chronic disease: how many lives can we save? Lancet 2005; 366(9496): 1578-82.

[7] Kokkinos PF, Giannelou A, Manolis A, Pittaras A. Physical activity in the prevention and management of high blood pressure. Hellenic J Cardiol 2009; 50(1): 52-9.

[8] Efstratopoulos AD, Voyaki SM, Baltas AA, et al. Prevalence, awareness, treatment and control of hypertension in Hellas, Greece: the Hypertension Study in General Practice in Hellas (HYPERTENSHELL) national study. Am J Hypertens 2006; 19(1): 53-60.

[9] Psaltopoulou T, Orfanos P, Naska A, Lenas D, Trichopoulos D, Trichopoulou A. Prevalence, awareness, treatment and control of hypertension in a general population sample of 26,913 adults in the Greek EPIC study. Int J Epidemiol 2004; 33(6): 1345-52.

[10] European Union. Special eurobarometer on sports and physical activity. Eurobarometer 334, 2010. Available from: http://ec.europa.eu/public_opinion/archives/ebs/ebs_334_en.pdf (12 December 2013, date last accessed).

[11] European Union. Special Eurobarometer on Tobacco. Eurobarometer 332, 2010. Available from: http://ec.europa.eu/ health/tobacco/docs/ebs332_en.pdf (24 January 2011, date last accessed).

[12] Kapantais E, Tzotzas T, Ioannidis I, et al. First national epidemiological survey on the prevalence of obesity and abdominal fat distribution in Greek adults. Ann Nutr Metab 2006; 50(4): 3308 .

[13] Tzotzas T, Kapantais E, Tziomalos K, et al. Epidemiological survey for the prevalence of overweight and abdominal obesity in Greek adolescents. Obesity (Silver Spring) 2008; 16(7): 1718-22.

[14] Chen X, Wang Y. Tracking of blood pressure from childhood to adulthood: a systematic review and meta-regression analysis. Circulation 2008; 117: 3171-80.

[15] Papathanasiou G, Georgoudis G, Papandreou M, et al. Reliability Measures of the Short International Physical Activity Questionnaire (IPAQ) in Greek young adults. hellenic J Cardiol 2009; 50: 283-94.

[16] Papathanasiou G, Georgoudis G, Georgakopoulos D, Katsouras C, Kalfakakou V, Evangellou A. Criterion-Related Validity of IPAQshort Against exercise capacity in young adults. Eur J Cardiovasc Prev Rehabil 2010; 17: 380-6.

[17] Haslam DW, James WP. Obesity. Lancet 2005; 366(9492): $1197-$ 209.

[18] Gooding HC, McGinty S, Richmond TK, Gillman MW, Field AE. Hypertension awareness and control among young adults in the National Longitudinal Study of Adolescent Health. J Gen Intern
Med 2014; 29(8): 1098-104.

[19] Kastorini CM, Milionis HJ, Goudevenos JA, Panagiotakos DB Mediterranean diet and coronary heart disease: is obesity a link? A systematic review. Nutr Metab Cardiovasc Dis 2010; 20(7): 53651.

[20] Kokkinos P, Panagiotakos DB, Polychronopoulos E. Dietary Influences on Blood Pressure: The Effect of the Mediterranean Diet on the Prevalence of Hypertension Body mass index and blood pressure. J Clin Hypertensive (Greenwich) 2005; 7(3): 165-72.

[21] World Health Organization. Fact Sheet No 311. Obesity and overweight. Geneva 2013. Available from: http://www.who.int/mediacentre/factsheets/fs311/en/ November 2013, date last accessed)

[22] World Health Organization. Noncommunicable diseases. Obesity data and statistics. Geneva 2013. Available from: http://www.euro.who.int/en/health-topics/noncommunicablediseases/obesity/data-and-statistics (16 January 2014, date last accessed)

[23] Martins D, Tareen N, Pan D, Norris K. The relationship between body mass index, blood pressure and pulse rate among normotensive and hypertensive participants in the third National Health and Nutrition Examination Survey (NHANES). Cell Mol Biol (Noisy-le-grand) 2003; 49(8): 1305-9.

[24] Saely CH, Riscb L, Frey F, et al. Body mass index, blood pressure and serum cholesterol in young Swiss men: an analysis on 56784 army conscripts. Swiss Med Wkly 2009; 139(35-36): 518-24.

[25] Jebb SA, Rennie KL, Cole TJ. Prevalence of overweight and obesity among young people in Great Britain. Public Health Nutr 2004; 7(3): 461-5.

[26] Savva SC, Kourides YA, Hadjigeorgioua C, Tornaritis MJ. Overweight and obesity prevalence and trends in children and adolescents in Cyprus 2000-2010. Obesity Res Clin Pract 2013; ORCP-348, article in press.

[27] Mensink GBM, Schienkiewitz A, Haftenberger M, Lampert T, Ziese T, Scheidt-Nave C. Overweight and obesity in Germany. Results of the German Health Interview and Examination Survey for Adults (DEGS1). Bundesgesundheitsblatt Gesundheits for schung Gesundheitsschutz 2013; 56(5-6): 786-94

[28] Hall JE. Guyton and Hall Textbook of Medical Physiology. $12^{\text {th }}$ ed. Philadelphia PA: Saunders-Elsevier 2011.

[29] Thethi T, Kamiyama M, Kobori $\mathrm{H}$. The link between the reninangiotensin-aldosterone system and renal injury in obesity and the metabolic syndrome. Curr Hypertens Rep 2012; 14(2): 160-9.

[30] Marcus Y, Shefer G, Stern N. Adipose tissue renin-angiotensinaldosterone system (RAAS) and progression of insulin resistance. Mol Cell Endocrinol 2013; 378: 1-14.

[31] Boden G. Obesity, insulin resistance and free fatty acids. Curr Opin Endocrinol Diabetes Obes 2011; 18(2): 139-43.

[32] Karpe F, Dickmann JR, Frayn KN. Fatty acids, obesity and insulin resistance: time for a reevaulation. Diabetes 2011; 60: 2441-9.

[33] Kim F, Tysseling KA, Rice J, et al. Free fatty acid impairment of nitric oxide production in endothelial cells is mediated by IKK $\beta$. Arterioscler Thromb Vasc Biol 2005; 25: 989-94.

[34] Sowers JR. Insulin resistance and hypertension. Am J Physiol Heart Circ Physiol 2004; 286(5): H1597-602.

[35] Rahmouni K, Correia MLG, Haynes WG, Mark AL. Obesityassociated hypertension: new insights into mechanisms. Hypertension 2005; 45: 9-14.

[36] Haynes GW. Role of leptin in obesity-related hypertension. Exp Physiol 2005; 90: 683-8.

[37] Grassi G. Leptin, sympathetic nervous system, and baroreflex function. Curr Hypertens Rep 2004; 6(3): 236-40. 
[38] Punjabi NM. The epidemiology of adult obstructive sleep apnea. Proc Am Thorac Soc 2008; 5: 136-43.

[39] Dopp JM, Reichmuth KJ, Morgan BJ. Obstructive sleep apnea and hypertension: mechanisms, evaluation and management. Curr Hypertens Rep 2007; 9(6): 529-34.

[40] Wolk R, Shamsuzzaman AS, Somers VK. Obesity, sleep apnea and hypertension. Hypertension 2003; 42: 1067-74.

[41] Oldridge NB. Economic burden of physical inactivity: healthcare costs associated with cardiovascular disease. Eur J Cardiovasc Prev Rehabil 2008; 15: 130-9.

[42] United States Department of Health and Human Services. Physical Activity Guidelines Advisory Committee. Physical Activity Guidelines Advisory Committee Report, 2008. Washington, DC, 2008. Available from: http://www.health.gov/paguidelines/report/pdf/CommitteeReport.p df (12 December 2013, date last accessed).

[43] Nocon M, Hiemann T, Muller-Riemenschneider F, Thalau F, Rolland S, Willich SN. Association of physical activity with allcause and cardiovascular mortality: a systematic review and metaanalysis. Eur J Cardiovasc Prev Rehabil 2008; 15: 239-46.

[44] Sjöström M, Oja P, Hagströmer M, Smith BJ, Bauman A. Healthenhancing physical activity across European Union countries: the Eurobarometer study. J Public Health 2006; 14: 291-300.

[45] Alexopoulos EC, Jelastopulu E, Aronis K, Dougenis D. Cigarette smoking among university students in Greece: a comparison between medical and other students. Environ Health Prev Med 2010; 15: 115-20.

[46] Haase A, Steptoe A, Sallis JF, Wardle J. Leisure-time physical activity in university students from 23 countries: associations with health beliefs, risk awareness, and national economic development. Prev Med 2004; 39: 182-90.

[47] Charilaou M, Karekla M, Constantinou M, Price S. Relationship between physical activity and type of smoking behavior among adolescents and young adults in Cyprus. Nicotine Tob Res 2009; 11: $969-76$.

[48] Skinner JS, Gaskill SE, Rankinen T, et al. Heart rate versus \%VO2max: age, sex, race, initial fitness, and training responseHERITAGE. Med Sci Sports Exerc 2003; 35(11): 1908-13.

[49] Chen J, Das S, Barlow CE, Grundy S, Lakoski SG. Fitness, fatness, and systolic blood pressure: data from the Cooper Center Longitudinal Study. Am Heart J 2010; 160(1): 166-70.

[50] Ekelund U, Luan J, Sherar LB, Esliger DW, Griew P, Cooper A. Moderate to vigorous physical activity and sedentary time and cardiometabolic risk factors in children and adolescents. JAMA 2012; 307(7): 704-12.

[51] Alomari MA, Keewan EF, Qhatan R, et al. Blood pressure and circulatory relationships with physical activity level in young normotensive individuals: IPAQ validity and reliability considerations. Clin Exp Hypertens 2011; 33(5): 345-53.

[52] Andersen LB. Blood pressure, physical fitness and physical activity in 17-year-old Danish adolescents. J Intern Med 1994; 236(3): 323 9.

[53] Aadahl M, Kjaer M, Jørgensen T. Associations between overall physical activity level and cardiovascular risk factors in an adult population. Eur J Epidemiol 2007; 22(6): 369-78.

[54] Kelley GA, Kelley KS, Tran ZV. The effects of exercise on resting blood pressure in children and adolescents: a meta-analysis of randomized controlled trials. Prev Cardiol 2003; 6(1): 8-16.

[55] Gaya AR, Silva P, Martins C, Gaya A, Ribeiro JC, Mota J. Association of leisure time physical activity and sports competition activities with high blood pressure levels: study carried out in a sample of Portuguese children and adolescents. Child Care Health Dev 2011; 37(3): 329-34.
[56] Bacon SL, Sherwood A, Hinderliter A, Blumenthal JA. Effects of exercise, diet and weight loss on high blood pressure. Sports Med 2004; 34(5): 307-16.

[57] Carnethon MR, Evans NS, Church TS, et al. Joint associations of physical activity and aerobic fitness on the development of incident hypertension: coronary artery risk development in young adults. Hypertension 2010; 56(1): 49-55.

[58] Fagard RH, Cornelissen VA. Effect of exercise on blood pressure control in hypertensive patients. Eur J Cardiovasc Prev Rehabil 2007; 14(1): 12-7.

[59] Lee PH1, Macfarlane DJ, Lam TH, Stewart SM. Validity of the International Physical Activity Questionnaire Short Form (IPAQSF): a systematic review. Int J Behav Nutr Phys Act 2011; 8: 115.

[60] Paffenbarger RS, Blair SN, Lee IM, Hyde RT. Measurement of physical activity to assess health effects in free-living populations. Med Sci Sports Exerc 1993; 25: 60-70.

[61] Tsioufis C, Kyvelou S, Tsiachris D, et al. Relation between physical activity and blood pressure levels in young Greek adolescents: the Leontio Lyceum Study. Eur J Public Health 2011; 21(1): 63-8.

[62] Kollias A, Antonodimitrakis P, Grammatikos E, Chatziantonakis N, Grammatikos EE, Stergiou GS. Trends in high blood pressure prevalence in Greek adolescents. J Hum Hypertens 2009; 23(6): 385-90.

[63] Papathanasiou G, Papandreou M, Galanos A, et al. Smoking and physical activity interrelations in health science students. Is smoking associated with physical inactivity in young adults? Hellenic J Cardiol 2012; 53(1): 17-25.

[64] Astrand PO, Rodahl K, Dahl HA, Stromme SB. Textbook of work physiology. Physiological basis of Exercise. Champagne, IL: Human Kinetics 2003.

[65] World Health Organization. Report on the global tobacco epidemic. Geneva, 2008. Available from: http://www.who.int/tobacco /mpower/mpower report_full_2008.pdf (14 November 2013, date last accessed).

[66] Sichletidis LT, Chloros D, Tsiotsios I, et al. High prevalence of smoking in northern Greece. Prim Care Respir J 2006; 15: 92-7.

[67] Green MS, Jucha E, luz Y. Blood pressure in smokers and nonsmokers: epidemiologic findings. Am Heart J 1986; 111: 93240 .

[68] Sandvik L, Eriksen G, Thaulow E. Long term effects of smoking on physical fitness and lung function: a longitudinal study of 1393 middle aged Norwegian men for seven years. BMJ 1995; 311: 715 8 .

[69] Okubo Y, MiyamotoY, Suwazono Y, Kobayashi E, Nogawa K. An association between smoking habits and blood pressure in normotensive Japan men. J Hum Hypertens 2002; 16: 91-6.

[70] Liu K, Ruth KJ, Flack JM, et al. Blood pressure in young black and whites: relevance of obesity and life style factors in determining differences. The CARDIA Study. Circulation 1996; 93: 60-6.

[71] Primatesta P, Falascheti E, Gupta S, Marmot MG, Poulter NR. Association between smoking and blood pressure. Evidence from the Health Survey for England. Hypertension 2001; 37: 187-93.

[72] Bolinder G, Faire U. Ambulatory $24 \mathrm{~h}$ blood pressure monitoring in healthy, middle aged smokeless tobacco users, smokers, and nontobacco users. Am J Hypertens 1998; 11: 1153-63.

[73] Vriz O, Nesbitt S, Krause L, et al. Smoking is associated with higher cardiovascular risk in young women than in men: the Tecumseh Blood Pressure Study. J Hypertens 1997; 15: 127-34.

[74] Mahmud A, Feely J. Effect of smoking on arterial stiffness and pulse pressure amplification. Hypertension 2003; 41: 183-7.

[75] Kim JW, Park CG, Hong SJ, et al. Acute and chronic effects of 
cigarette smoking on arterial stiffness. Blood Press 2005; 14: 80-5.

[76] Benowitz NL, Gourlay SG. Cardiovascular toxicity of nicotine: Implications for nicotine replacement therapy. J Am Coll Cardiol 1997; 29: 1422-31.

[77] Lucini D, Bertocchi F, Malliani A, Pagani M. A controlled study of the autonomic changes produced by habitual cigarette smoking in healthy subjects. Cardiovascular Res 1996; 31: 633-9.
[78] Niedermaier ON, Smith ML, Beightol LA, Zukowska-Grojec Z, Goldstein DS, Eckberg DL. Influence of cigarette smoking on human autonomic function. Circulation 1993; 88: 562-71.

[79] Hayano J, Yamada M, Sakakibara Y, et al. Short and long-term effects of cigarette smoking on heart rate variability. Am J Cardiol 1990; 65: 84-8.

(C) Papathanasiou et al.; Licensee Bentham Open.

This is an open access article licensed under the terms of the Creative Commons Attribution Non-Commercial License (http://creativecommons.org/licenses/by-nc/3.0/) which permits unrestricted, non-commercial use, distribution and reproduction in any medium, provided the work is properly cited. 